GRASAS Y ACEITES 68 (4)

October-December 2017, e224

ISSN-L: 0017-3495

doi: http://dx.doi.org/10.3989/gya.0552171

\title{
Optimization of methanol crystallization for highly efficient separation of palmitic acid from palm fatty acid mixture using response surface methodology
}

\author{
A.A.W. Japir ${ }^{\mathrm{a}, \mathrm{b}}$, J. Salimon ${ }^{\mathrm{a}}$, D. Derawi ${ }^{\mathrm{a}}$, B.H. Yahaya ${ }^{\mathrm{c}}$, M.S.M. Jamil ${ }^{\mathrm{a}}$ and M.R. Yusop ${ }^{\mathrm{a}, \mathrm{c}, \bowtie}$ \\ ${ }^{a}$ School of Chemical Sciences and Food Technology, Faculty of Science and Technology, University \\ Kebangsaan Malaysia, 43600 Bangi, Selangor, Malaysia \\ ${ }^{b}$ Department of Chemistry, Faculty of Education, Thamar University, Thamar, Yemen \\ 'Kluster Perubatan Regeneratif, Institut Perubatan dan Pergigian Termaju, Universiti Sains Malaysia, \\ 13200 Bertam Kepala Batas, Pulau Pinang, Malaysia. Tel: 0060102678586 \\ ${ }^{\square}$ Corresponding author: rahimi@ukm.edu.my
}

Submitted: 05 May 2017; Accepted: 19 September 2017

\begin{abstract}
SUMMARY: The objective of the current study was to develop parameters for the separation of palmitic acid (PA) from a crude palm oil saturated fatty acid (SFAs) mixture by using the methanol crystallization method. The conditions of methanol crystallization were optimized by the response surface methodology (RSM) with the D-optimal design. The procedure of developing the solvent crystallization method was based on various different parameters. The fatty acid composition was carried out using a gas chromatography flame ionization detector (GC-FID) as fatty acid methyl esters. The highest percentage of SFAs was more than $96 \%$ with the percentage yield of $87.5 \%$ under the optimal conditions of fatty acids-to-methanol ratio of $1: 20(\mathrm{w} / \mathrm{v})$, the crystallization temperature of $-15^{\circ} \mathrm{C}$, and the crystallization time of 24 hours, respectively. The composition of separated SFAs in the solid fraction contains $96.7 \%$ of palmitic acid $\left(\mathrm{C}_{16: 0}\right)$ as a dominant component and $3.3 \%$ of stearic acid $\left(\mathrm{C}_{18: 0}\right)$. The results showed that utilizing methanol as a crystallization solvent is recommended because of its high efficiency, low cost, stability, availability, comparative ease of recovery and its ability to form needle-like crystals which have good filtering and washing characteristics.
\end{abstract}

KEYWORDS: Biodiesel; D-optimal design; Methanol crystallization; Palmitic acid; Response surface methodology (RSM)

RESUMEN: Optimización de la cristalización con metanol para una separación altamente eficiente del ácido palmítico en mezclas de ácidos grasos de palma usando metodología de superficie de respuesta. El objetivo del presente estudio fue desarrollar parámetros para la separación de ácido palmítico (PA) en mezclas de ácidos grasos saturados (SFAs) de aceites de palma crudo mediante el método de cristalización con metanol. Las condiciones de cristalización con metanol se optimizaron utilizando la metodología de superficie de respuesta (RSM) con el diseño D-Optimal. El procedimiento de desarrollo del método de cristalización con disolvente se basó en diversos parámetros diferentes. La composición de ácidos grasos se llevó a cabo por cromatografía de gases (GC-FID) como ésteres metílicos de ácidos grasos usando un detector de ionización de llama. El porcentaje más alto de SFAs fue mayor del $96 \%$ con un rendimiento porcentual de 87,5\% bajo las condiciones óptimas de relación de ácidos grasos:metanol de 1:20 (p/v), una temperatura de cristalización de $-15^{\circ} \mathrm{C}$ y un tiempo de cristalización de 24 horas. La composición de la fracción de SFAs separada en fracción sólida contiene 96,7\% de ácido palmítico (C16:0) como principal componente y 3,3\% de ácido esteárico (C18:0). Los resultados mostraron recomendar metanol como disolvente de cristalización debido a su alta eficiencia, bajo coste, estabilidad, disponibilidad, facilidad comparativa de recuperación y su capacidad para formar cristales de aguja que tienen buenas características de filtración y lavado.

PALABRAS CLAVE: Ácido palmítico; Biodiesel; Cristalización en metanol; Diseño D-optimal; Metodología de superficie de respuesta (RSM)

ORCID ID: Japir AAW http://orcid.org/0000-0002-8261-7981, Salimon J http://orcid.org/0000-0002-1577-8478, Derawi D http://orcid.org/0000-0003-4967-8122, Yahaya BH http://orcid.org/0000-0002-3295-9676, Jamil MSM http://orcid.org/0000-0003-0745-0787, Yusop MR http://orcid.org/0000-0002-8843-8677

Citation/Cómo citar este artículo: Japir AAW, Salimon J, Derawi D, Yahaya BH, Jamil MSM, Yusop MR. 2107. Optimization of methanol crystallization for highly efficient separation of palmitic acid from palm fatty acid mixture using response surface methodology. Grasas Aceites 68 (4), e224. http://dx.doi.org/10.3989/gya.0552171

Copyright: (C2017 CSIC. This is an open-access article distributed under the terms of the Creative Commons Attribution (CC-by) Spain 3.0 License. 


\section{INTRODUCTION}

Palmitic acid (PA), also called hexadecanoic acid, is an example of saturated fatty acids (SFAs) which are found in plants and animals. Its chemical formula is $\mathrm{CH}_{3}\left(\mathrm{CH}_{2}\right)_{14} \mathrm{COOH}$, and it is regarded as a major component in the composition of palm oil. It can also be found in several products such as butter, cheeses, meats, and dairy products as an additive. PA is widely used in many industrial fields such as soaps, cosmetics, and release agents (Henderson and Osborne, 2000). Recently, its use has been extended to numerous modern applications such as feedstock to produce biodiesel (Saravanan et al., 2016), as an additive in pulmonary surfactant synthesis (Nakahara et al., 2011), as an additive in preparations of composite-based formula (Zhang et al., 2014), as a phase change material for latent heat storage and a phase change energy storage material (Fang et al., 2012).

Several methods had been reported for separating a fatty acid mixture with varying yields, such as adsorption chromatography (Maddikeri et al., 2012), enzymatic splitting (Kempers et al., 2013), molecular distillation (Cermak et al., 2012), low-temperature crystallization (Brown and Kolb, 1955), urea complexation (Salimon et al., 2012), and fractional crystallization from solvents (Strohmeier et al., 2014). However, the most efficient and simplest separation method to obtain SFA concentrates as free fatty acids is fractional crystallization from solvents. This is a wellestablished technique to remove monounsaturated and polyunsaturated fatty acids and SFAs such as lauric acid and myristic acid which are a part of the composition of the palm fatty acid mixture. Fractional crystallization from methanol is advantageous because of its low cost, easy process and ability to recycle methanol.

A comprehensive review of novel separation techniques for separation and purification of fatty acids and their derivatives was conducted by Wanasundara et al., (2005). The major techniques for separating saturated and unsaturated fatty acids are low-temperature crystallization, distillation, in addition to the complex formation and precipitation with urea. Fatty acids are difficult to separate because of their slightly close molecular weights, similar sets of functional groups, and fluxional structures. The molecular weights of the seven fatty acids in palm oil are $200.32 \mathrm{~g} /$ mol (lauric acid), $228.37 \mathrm{~g} / \mathrm{mol}$ (myristic acid), $256.42 \mathrm{~g} / \mathrm{mol}$ (palmitic acid), $284.48 \mathrm{~g} / \mathrm{mol}$ (stearic acid), $282.46 \mathrm{~g} / \mathrm{mol}$ (oleic acid), $280.45 \mathrm{~g} / \mathrm{mol}$ (linoleic acid), and $278.43 \mathrm{~g} / \mathrm{mol}$ (linolenic acid). The solubilities, boiling points, and densities of the fatty acids are somewhat similar and there is no simple basis for separation to achieve high purities. However, separation methods such as winterization, distillation, and chromatography are based on these physical properties (Bowden and Gupta 2014).

It is well known that higher unsaturated acids are much more soluble than their corresponding saturated counterparts and may be partially separated from a mixture (Wanasundara et al., 2005). Thus, the separation of a fatty acid mixture into two fractions using solvent crystallization is based on the difference in their solubility in specific polar organic solvents such as methanol, ethanol and acetone or a mixture of organic solvents (Strohmeier et al., 2014).

Response surface methodology (RSM) is a group of statistical and mathematical techniques which are suitable for modeling and analysis in applications where a dependent variable of interest is affected by numerous independent variables and the aim is to optimize this dependent variable (Montgomery, 2001). RSM assists in evaluating the influence of numerous variables and their interactions on dependent variables. It can also help in finding the relationship between process variables and in building a mathematical model which perfectly describes the overall process (Myers et al., 2009).

In this study, the methanol crystallization of a mixture of fatty acids of high free fatty acid crude palm oil was conducted to produce palmitic acid (PA) with high yield and percentage. The influence of FAs-to-methanol ratio $\left(X_{1}\right)$, crystallization temperature $\left(X_{2}\right)$ and crystallization time $\left(X_{3}\right)$ on the yield $\%$ of SFAs $\left(Y_{1}\right)$, percentage of SFAs $\left(Y_{2}\right)$, percentage of PA $\left(Y_{3}\right)$ was systematically analyzed using the RSM.

\section{MATERIALS AND METHODS}

\subsection{Materials}

Crude palm oil was provided by Sime Darby Company, Carey Island, Selangor - Malaysia. Fatty acid methyl ester (FAME) standards were purchased from Sigma-Aldrich Chemical Co. Inc (St. Louis, MO, USA). There are other chemicals and solvents used in this study such as methanol, n-hexane, ethanol, and sodium sulphate which were either analytical grade or high performance liquid chromatography (HPLC) grade used without further purification.

\subsection{Preparation of free fatty acids (FFAs)}

Approximately $25 \mathrm{~g}$ of high free fatty acid crude palm oil was placed in the flask with $150 \mathrm{~mL}$ of a hydrolysis solution which contains 
ethanolic potassium hydroxide $(1.75 \mathrm{M})$, and ethanol (150 mL: 90\% v/v). The hydrolysis reaction was carried out in a $250 \mathrm{~mL}$ two-neck roundbottom flask at a reaction temperature of $70{ }^{\circ} \mathrm{C}$ and reaction time of $2 \mathrm{~h}$. After this, the hydrolysis was done, and unsaponifiable matters were separated by adding $100 \mathrm{~mL}$ of water with $50 \mathrm{~mL}$ of hexane to the mixture. The soap containing the aqueous alcohol phase was acidified by adding $\mathrm{HCl} 6 \mathrm{~N}(\sim 60 \mathrm{~mL})$ to $\mathrm{pH}=1$, and recovery of free fatty acids by extraction with a non-polar solvent as hexane. About $(3 \times 25 \mathrm{~mL})$ of the distilled water was used to wash the extracted fatty acid mixture to neutral $\mathrm{pH}$. A separating funnel was also used to remove and discard the resulting lower layer. The upper organic layer containing FFAs was dried with anhydrous sodium sulphate, and hexane was evaporated under reduced pressure using a vacuum rotary evaporator at $35^{\circ} \mathrm{C}$ (Salimon et al., 2011). After that, the free fatty acid percentage (\% FFAs) was determined (Prasanth Kumar and Gopala Krishna, 2015).

\subsection{Separation of saturated fatty acid crystallization (preliminary test)}

Firstly, the following procedure was performed to select the effective factors for the separation of saturated fatty acids. The crystallization of palm fatty acid mixture (PFAM) was carried out with a proper beaker in a refrigerator provider to control the temperature. The fatty acid mixture was crystallized from aqueous methanol (95\%). For the solute, solvent ratios were varied from $1: 5 \mathrm{w} / \mathrm{v}$ to 1:25 (g:mL). The temperatures of crystallization were also varied from -20 to $5{ }^{\circ} \mathrm{C}$, while crystallization time was varied from 4 to $30 \mathrm{~h}$ as shown in Table 1. The mixture of liquid and crystals was filtered by a Buchner funnel under reduced pressure. The funnel was pre-cooled to the same crystallization temperature as the solvent and FFAs. The crystals were washed once on the filter with the proper amount of a pre-cooled methanol to the same temperatures of crystallization of the chilled liquid and crystals. The solvent was evaporated from the solid and liquid fractions under reduced pressure. Then, the same procedure was repeated one time with separated solid fractions to concentrate SFAs.

\subsection{Experimental design}

In this study, three independent variables were determined under the same experimental operating conditions to verify using crystallization from the methanol of saturated fatty acids (solid fraction) obtained from the second crystallization of palm fatty acid mixture (PFAM). The independent variables in this study were FAs-to- $\mathrm{MeOH}$ ratio $(\mathrm{g} / \mathrm{mL}$, $\left.X_{1}\right)$, temperature $\left({ }^{\circ} \mathrm{C}, X_{2}\right)$, and time $\left(\mathrm{h}, X_{3}\right)$. In a typical experiment, $10 \mathrm{~g}$ of SFAs were crystallized from methanol. The FAs-to-methanol ratios were varied from $1: 10 \mathrm{~g} \mathrm{~mL}^{-1}$ to $1: 20\left(\mathrm{~g} \mathrm{~mL}^{-1}\right)$. Temperatures of crystallization were also varied from -15 to 0 ${ }^{\circ} \mathrm{C}$. Crystallization time was varied from 8 to 24 $\mathrm{h}$, as shown in Table 2. The mixture was left in the refrigerator for a specific time and the liquid and crystals were filtered by the Buchner funnel under reduced pressure. The funnel was pre-cooled to the same crystallization temperature as the solvent and FFAs. The crystals were washed once on the filter with the proper amount of a pre-cooled methanol to the same temperature crystallization of the chilled liquid and crystals. Methanol was evaporated from the solid and liquid fractions under reduced pressure. Then, this process was repeated one more time with the solid fraction (palmitic acid), which indicates that there is a need for double crystallization to increase the percentage of palmitic acid. After selecting the range of variables in our lab, and repeating the experiment at optimal parameters, the RSM was used statically to optimize the responses. Therefore, the total crystallization was repeated four times.

\subsection{Model fitting and statistical analysis}

In this study, the RSM with the D-optimal design was used to optimize the dependent variables in solid fractions after methanol crystallization was carried out. The yield $\%$ of SFAs $\left(Y_{1}\right)$, the percentage of SFAs $\left(\mathrm{Y}_{2}\right.$ in \%), and PA $\left(\mathrm{Y}_{3}\right.$ in $\%$ ) are given in Equations 2, 3, and 4, respectively. Moreover, the selection of the range of the independent variables was based on a primary study which had been conducted in our lab and will be published elsewhere.

The independent variables were FAs-to- $\mathrm{MeOH}$ ratio $(\mathrm{w} / \mathrm{v}),\left(X_{1}\right)$, temperature $\left({ }^{\circ} \mathrm{C}\right)\left(X_{2}\right)$ and time (h) $\left(X_{3}\right)$. The codes and range of these factors are shown in Table 2. A quadratic polynomial

TABLE 1. Experimental range and levels of independent variables for separation of saturated fatty acids

\begin{tabular}{lcccc}
\hline & & \multicolumn{3}{c}{ Variable levels } \\
\cline { 3 - 5 } Independent variable & Coding & $\mathbf{- 1}$ & $\mathbf{0}$ & $\mathbf{1}$ \\
\hline FAs -to- MeOH ratio $(\mathrm{w} / \mathrm{v})(\mathrm{g} / \mathrm{mL})$ & $X_{1}$ & 5 & 15 & 25 \\
Crystallization temperature $\left({ }^{\circ} \mathrm{C}\right)$ & $X_{2}$ & -20 & 0 & 5 \\
Crystallization time $(\mathrm{h})$ & $X_{3}$ & 4 & 16 & 30 \\
\hline
\end{tabular}


TABLE 2. Experimental range and levels of independent variables for D-optimal design.

\begin{tabular}{lcccc}
\hline & & \multicolumn{3}{c}{ Range and level } \\
\cline { 3 - 5 } Independent variable parameters & code & $\mathbf{- 1}($ Low) & $\mathbf{0}$ (Center) & $\mathbf{+ 1}($ High) \\
\hline FAs-to-MeOH ratio $(\mathrm{w} / \mathrm{v})\left(\mathrm{g} \mathrm{mL}^{-1}\right)$ & $X_{1}$ & 10 & 15 & 20 \\
Crystallization temperature $\left({ }^{\circ} \mathrm{C}\right)$ & $X_{2}$ & -15 & -7.5 & 0 \\
Crystallization time $(\mathrm{h})$ & $X_{3}$ & 8 & 16 & 24 \\
\hline
\end{tabular}

regression model was assumed for predicting individual $Y$ variables. The model suggested for each response of $Y$ as given below in Equation (1) (Montgomery, 2001).

$$
Y=\beta_{o}+\sum_{i=1}^{k} \beta_{i} X_{i}+\sum_{i=1}^{k} \beta_{i i} X_{i}^{2}+\sum_{i=1}^{k} \cdot \sum_{j \geq 1}^{k} \beta_{i j} X_{i} X_{j}+\varepsilon(1)
$$

Where $Y$ is the dependent variable (response), $\beta$; $\beta \mathrm{i} ; \beta \mathrm{ii}$; and $\beta \mathrm{ij}$ are constant, linear, quadratic and interaction regression coefficient terms, respectively. $\mathrm{K}$ represents the number of the independent variables "xi", and " $\varepsilon$ " is the residual or the random error. Design-Expert version 6.0.10 (Stat Ease, USA) was used for analysis of variance (ANOVA), multiple regression analysis, and analysis of ridge maximum of data in the response surface regression (RSREG) procedure. Thus, ANOVA and the coefficient of determination $R^{2}$ were used to determine the goodness of fit of the model. Contour plot and response surface were enhanced by utilizing a suitable quadratic polynomial equation achieved from the RSREG analysis and holding the independent variables at a constant value and changing the level of other variables (Jiang et al., 2006; Permukaan et al., 2015; Wu et al., 2008).

\subsection{Preparation of fatty acid methyl esters (FAME)}

About $0.008 \mathrm{~mol}(2 \mathrm{~g})$ of palmitic acid were added to a small $(50 \mathrm{~mL})$ two-neck round-bottom flask, equipped with a standard taper joint (19/38) and a short condenser. Then, $0.2 \mathrm{~mol}(8.7 \mathrm{~mL})$ methanol was added with $0.01 \mathrm{~mol}(0.3 \mathrm{~mL})$ of $\mathrm{HCl} 37 \%$, and this was followed by adding $1.4 \times 10^{-}$ ${ }^{2} \mathrm{~mol}(1.5 \mathrm{~mL})$ of toluene. After that, the mixture was refluxed at $65^{\circ} \mathrm{C}$ for 1.5 hour. Then, it was transferred to a separating funnel, $10 \mathrm{~mL}$ distilled water and $15 \mathrm{~mL}$ of hexane were added to the mixture. Afterward, the mixture was left to stand till there were two complete layers. Then, the upper layer was separated and dried using anhydrous sodium sulphate $\mathrm{Na}_{2} \mathrm{SO}_{4}$ overnight. Thus, hexane was recovered under reduced pressure by using a vacuum rotary evaporator at $35^{\circ} \mathrm{C}$ (Japir et al., 2016; Japir et al., 2017).

\subsection{GC-FID analyses}

GC analyses were performed using gas chromatograph (Model 5890 SERIES II GC, HEWLETT PACKARD, USA) software equipped with a flame ionization detector (FID) and a BPX70 fused silica capillary column $(30 \mathrm{~m}, 0.25 \mathrm{~mm}$ i.d., $0.25-\mu \mathrm{m}$ film thickness). The injector temperature was maintained at $280{ }^{\circ} \mathrm{C}$. Operating conditions were as follows: helium as the carrier gas was at a flow rate of $1 \mathrm{~mL} / \mathrm{min}$, injection volume $1 \mu \mathrm{L}$ and a split ratio of $60: 1$. The oven temperature was maintained at $120^{\circ} \mathrm{C}$, and it was increased to 245 ${ }^{\circ} \mathrm{C}$ and held for $15 \mathrm{~min}$ at a rate of $3{ }^{\circ} \mathrm{C}$ per minute for $56.6 \mathrm{~min}$ of analysis. The FAME peaks were classified and quantified by comparing their peak areas and retention times with that of pure standard FAME (Japir et al., 2016).

\section{RESULTS AND DISCUSSION}

\subsection{Composition of high free fatty acid crude palm oil}

After hydrolysis, the composition of palm fatty acid mixture (PFAM) consisted of $0.2 \%$ lauric $\left(\mathrm{C}_{12: 0}\right), 0.9 \%$ myristic $\left(\mathrm{C}_{14: 0}\right), 42.4 \%$ palmitic $\left(\mathrm{C}_{16: 0}\right)$, $4.3 \%$ stearic $\left(\mathrm{C}_{18: 0}\right), 42.1 \%$ oleic $\left(\mathrm{C}_{18: 1}\right), 9.8 \%$ linoleic $\left(\mathrm{C}_{18: 2}\right)$ and linolenic acid $\left(\mathrm{C}_{18: 3}\right) 0.3 \%$.

\subsection{Separation of saturated fatty acids (SFAs)}

The separation of saturated fatty acids was performed using crystallization from methanol of a palm fatty acid mixture (PFAM) under certain separation conditions as provided in Table 1. Thus, separation depends on the solubility differences between the various components of the mixture of fatty acids. It has long been known that higher SFAs are much less soluble than analogous unsaturated fatty acids. This solubility behavior of PFAM may be explained by considering the polarity and hydrogen bonding properties of mixture contents. As a fatty acid, long chain saturated fatty acids such as stearic acid and palmitic acid are relatively non-polar compounds. However, short chain saturated fatty acids such as lauric acid and myristic acid have more polarity compared to 
stearic and palmitic acid. Concerning the monosaturated fatty acids, polyunsaturated fatty acids are more polar than saturated fatty acids. The solubility of a palm fatty acid mixture in methanol in order to increase polarity comprises linolenic acid, linoleic acid, oleic acid, lauric acid, myristic acid, palmitic acid, and stearic acid. Therefore, based on the principle that "like dissolve like", unsaturated fatty acids will be more soluble than saturated fatty acids in methanol.

As a result, separation could happen because of the high solubility of oleic acid, linoleic, and linolenic in methanol. However, saturated fatty acids, especially palmitic acid, are poorly soluble in methanol and preferentially crystallized out. The slightly increasing amount of stearic acid is due to co-crystallization occurring from the solubility of other acids in PFAM. Lauric and myristic acids are saturated acids, but their concentration is very low, while their solubility is higher than that in palmitic acid. As a result, they were soluble in methanol, thus making the palmitic acid an enriched sample.

The optimal variables were found to be $1: 15$ $(\mathrm{g} / \mathrm{mL})$ for FAs-to- $\mathrm{MeOH}$ ratio, $-15^{\circ} \mathrm{C}$ for crystallization temperature, and $24 \mathrm{~h}$ for time of crystallization that had been performed in the preliminary test for separating saturated fatty acids from PFAM and obtaining the range of variables in order to conduct further separation and purification of palmitic acid. It can be observed from gas chromatography that palmitic acid was concentrated gradually as shown in Figure 1, where the percentage of PA increased from $42.4 \%$ to $90 \%$ in the solid fraction after the double crystallization of PFAM and solid fraction, respectively. Then, this solid fraction was used for further separation to obtain concentrated palmitic acid analyzed by the D-optimal design.

\subsection{Separationand solubility of palm fatty acids mixture}

Separation of PFAM by crystallization from methanol depends on the differences in solubility among the various components of the mixture of fatty acids. Since higher saturated fatty acids are much less soluble than corresponding unsaturated fatty acids, the advantage has often been taken to partially separate mixtures, as shown in Table 3. This solubility behavior of PFAM may be explained by considering the polarity and hydrogen bonding properties of the mixture contents. As fatty acids, long chain saturated fatty acids, such as stearic acid and palmitic acid, are relatively non-polar compounds. However, short chain saturated fatty acids, such as lauric acid and myristic acid, exhibit more polarity compared to stearic and palmitic acids. Concerning monosaturated fatty acids and polyunsaturated fatty acids, they are characterized to be more polar than saturated fatty acids. The solubility of a palm fatty acid mixture in methanol, ordered in terms of its increased polarity, displays this order: linolenic acid, linoleic acid, oleic acid, lauric

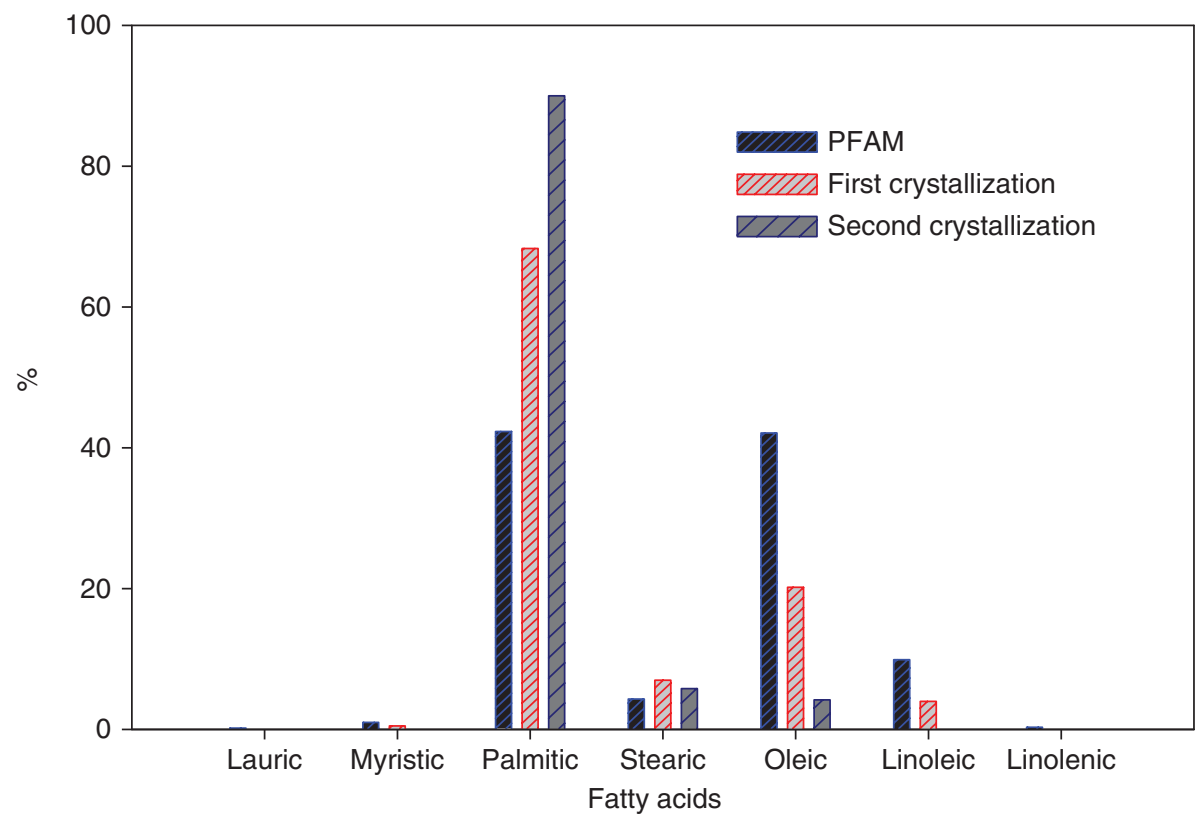

FIGURE 1. Fatty acid profiles of palm fatty acid mixture, saturated fatty acids (first crystallization) and saturated fatty acids (second crystallization). 
TABLE 3. Solubility of fatty acids ( $\mathrm{g}$ acid/100-g solution) in methanol at different temperatures

\begin{tabular}{|c|c|c|c|c|c|c|c|}
\hline \multirow[b]{2}{*}{ Temp $\left({ }^{\circ} \mathrm{C}\right)^{*}$} & \multicolumn{7}{|c|}{ Solubility } \\
\hline & Lauric acid & Myristic acid & Palmitic acid & Stearic acid & Oleic acid & Linoleic acid & Linolenic acid \\
\hline 10 & - & - & 1.310 & 0.259 & - & - & - \\
\hline 0 & - & 1.84 & 0.396 & 0.092 & - & - & - \\
\hline-10 & 2.83 & 0.826 & 0.146 & 0.032 & - & - & - \\
\hline-20 & 1.70 & 0.344 & 0.063 & 0.010 & 4.02 & - & - \\
\hline-30 & 0.823 & 0.153 & 0.020 & - & 0.708 & - & - \\
\hline-40 & - & - & - & - & 0.329 & - & - \\
\hline-50 & - & - & - & - & 0.089 & 2.52 & - \\
\hline-60 & - & - & - & - & 0.052 & 0.925 & - \\
\hline-62 & - & - & - & - & - & - & 1.76 \\
\hline-70 & - & - & - & - & 0.032 & 0.394 & - \\
\hline
\end{tabular}

TABLE 4. Palm fatty acid melting points

\begin{tabular}{lccccccc}
\hline \multicolumn{1}{c}{ Fatty acids } \\
\hline & Lauric acid & Myristic acid & Palmitic acid & Stearic acid & Oleic acid & Linoleic acid & Linolenic acid \\
\hline Melting point $\left({ }^{\circ} \mathrm{C}\right)$ & 44.8 & 54.4 & 62.9 & 70.1 & 16.3 & $6.5-$ & $12.8-$ \\
\hline
\end{tabular}

acid, myristic acid, palmitic acid, and stearic acid. Therefore, based on the principle that "like dissolve like", unsaturated fatty acids will be more soluble than saturated fatty acids in methanol.

The metling point of fatty acids changes frequently with the type and degree of unsaturation. Therefore, it is probable to separate the mixture of fatty acids into saturated and unsaturated fatty acids. Furthermore, the solubility of fatty acids increases with the increase in temperature, and it is mainly reflected by their melting points: high melting point fatty acids are less soluble than low melting point fatty acids. For example, in $\mathrm{C} 18$ fatty acid series, stearic $\operatorname{acid}_{(18: 0)}$ melts at $70.1^{\circ} \mathrm{C}$, oleic $\operatorname{acid}_{(18: 1)}$ at $16.3{ }^{\circ} \mathrm{C}$, linoleic $_{(18: 2)}$ at $-6.5{ }^{\circ} \mathrm{C}$ and linolenic $(18: 3)$ at $-12.8^{\circ} \mathrm{C}$ as shown in Table 4 . Consequently, an increase in the unsaturated fatty acid in the mixture usually leads to decreasing the melting point of the mixture, while increasing the solubility of unsaturated fatty acid in methanol decreases it.

\subsection{Separation of palmitic acid}

The PA concentrate was produced by the methanol crystallization method, using SFAs that had been previously obtained after selecting the optimal separation factor and the range of independent variables in our lab. The aim of this procedure is to obtain SFAs enriched in PA with the highest yield \% and percentage of PA. In this study, differences in variables which influence methanol crystallization such as FAs-to-MeOH ratio $\left(X_{1}, \mathrm{w} / \mathrm{v}\right)$, temperature $\left(X_{2},{ }^{\circ} \mathrm{C}\right)$ and time $\left(X_{3}, \mathrm{~h}\right)$ were investigated to achieve optimal parameters for the separation and concentration of palmitic acid using the RSM with the D-optimal design. Table 5 represents the data on the fatty acid composition in the solid fraction of SFAs that was obtained from the second crystallization from methanol of PFAM for all 18 experiments. The results demonstrated that $\mathrm{PA} \%$ increased from $90 \%$ to $96.7 \%$ whereas stearic acid decreased from $5.8 \%$ to $3.31 \%$. However, the monosaturated fatty acid (MUSFA) oleic acid (OA) was not observed in the final product at the optimal conditions.

It can be seen in Table 5, for the samples with a high ratio of FAs-to-MeOH, the percentage of MUFA (OA) in the solid fraction of SFAs slightly decreased as the solubility of oleic acid increased compared to palmitic acid and stearic acid under the same conditions. Consequently, the increased volume of methanol with lower temperature resulted in greater tendencies of palmitic acid and stearic acid to form crystal adducts than oleic acid. This could be due to the variation in their solubilities under the same conditions. However, total elimination of stearic acid by methanol crystallization may be impossible because of its similar solubility with palmitic acid. The PA $\%$ extracted from the SFAs phase was slightly high, thus exceeding $95 \%$, with a recovery yield of over $87 \%$ under optimal conditions (Table 5). Such a result demonstrates that experimental operating conditions are applicable to the production of high percentage yields and purity of palmitic acid from PFAM using methanol crystallization. However, it is slightly challenging to eliminate all stearic acid to achieve $100 \%$ purity of PA in the concentrate by using methanol 
Optimization of methanol crystallization for highly efficient separation of palmitic acid from palm fatty acid $\bullet 7$

TABLE 5. D-optimal design and experimental run for solid fraction of high free fatty acid crude palm oil

\begin{tabular}{|c|c|c|c|c|c|c|c|c|}
\hline \multirow[b]{3}{*}{ Run } & \multicolumn{3}{|c|}{ Variable levels, $X$} & \multicolumn{5}{|c|}{ Responses, $Y$} \\
\hline & $\begin{array}{l}\text { FAs-to- } \\
\text { MeOH }^{\text {a }}\end{array}$ & Temp. ${ }^{b}$ & Time $^{\cdot c}$ & $Y_{1}{ }^{\mathrm{d}}$, Yield & $Y_{2}^{\mathrm{e}}, \mathbf{S F A s} \%$ & $Y_{3}^{\mathrm{f}}, \mathbf{P A} \%$ & $Y_{4}^{\mathrm{g}}, \mathbf{S A} \%$ & $Y_{5}^{\mathrm{h}}$, MUSFA $\%$ \\
\hline & $X_{1}$ & $X_{2}$ & $X_{3}$ & $\%$ & $\left(C_{16: 0}+C_{18: 0}\right) \%$ & $\left(C_{16: 0}\right) \%$ & $\left(C_{18: 0}\right) \%$ & $\left(C_{18: 1}\right) \%$ \\
\hline 1 & 10 & 0 & 8 & 69.3 & 98.9 & 94.1 & 4.8 & 1.1 \\
\hline 2 & 20 & 0 & 8 & 66.3 & 99.6 & 95.0 & 4.6 & 0.4 \\
\hline 3 & 10 & -15 & 24 & 82.2 & 98.7 & 94.6 & 4.1 & 1.3 \\
\hline 4 & 20 & 0 & 24 & 75.2 & 99.5 & 93.9 & 5.6 & 0.5 \\
\hline 5 & 10 & -15 & 8 & 60.8 & 99.4 & 94.6 & 4.8 & 0.6 \\
\hline 6 & 10 & 0 & 24 & 81.4 & 98.3 & 92.8 & 5.5 & 1.7 \\
\hline 7 & 10 & 0 & 8 & 72.3 & 98.9 & 94.3 & 4.6 & 1.1 \\
\hline 8 & 10 & -15 & 8 & 61.2 & 99.5 & 95.0 & 4.5 & 0.5 \\
\hline 9 & 17.5 & -7.5 & 20 & 75.8 & 99.4 & 93.7 & 5.7 & 0.6 \\
\hline 10 & 10 & -7.5 & 16 & 77.1 & 98.4 & 92.7 & 5.7 & 1.6 \\
\hline 11 & 20 & -15 & 24 & 87.5 & 100 & 96.7 & 3.3 & 0.0 \\
\hline 12 & 15 & 0 & 16 & 74.9 & 98.2 & 90.1 & 8.1 & 1.8 \\
\hline 13 & 10 & 0 & 24 & 81.6 & 98.0 & 92.2 & 5.8 & 2.0 \\
\hline 14 & 15 & -15 & 24 & 84.8 & 99.3 & 94.2 & 5.1 & 0.7 \\
\hline 15 & 20 & -15 & 8 & 69.1 & 99.2 & 94.3 & 4.9 & 0.8 \\
\hline 16 & 20 & -15 & 16 & 80.9 & 99.3 & 92.9 & 6.4 & 0.7 \\
\hline 17 & 20 & 0 & 8 & 63.3 & 99.5 & 94.4 & 5.1 & 0.5 \\
\hline 18 & 15 & -7.5 & 8 & 62.1 & 99.4 & 93.8 & 5.6 & 0.6 \\
\hline
\end{tabular}

${ }^{\mathrm{a}}$ Fatty acids-to-methanol ratio (w/v), ${ }^{\mathrm{b}}$ temperature $\left({ }^{\circ} \mathrm{C}\right),{ }^{\mathrm{c}}$ time $(\mathrm{h}),{ }^{\mathrm{d}}$ The yield of saturated fatty acids $(\mathrm{SFAs}),{ }^{\mathrm{e}}$ The percentage recovery of saturated fatty acids (SFAs), ${ }^{\mathrm{f}}$ The percentage of PA in SFAs, ${ }^{\mathrm{g}}$ The percentage of SA in SFAs, ${ }^{\mathrm{h}}$ The percentage of MUSFA (oleic acid) in SFAs.

crystallization, which is closely due to the chemistry of PA and stearic acid.

In order to increase the purity of palmitic acid to $99.9 \%$, molecular distillation could be applied to separate palmitic from stearic acids and produce high purity for both fatty acids. Yet, molecular distillation cannot be applied to separate PFAM due to closeness of their boiling points. However, molecular distillation can be applied to purify palmitic acid after separating lauric, myristic, oleic, and linoleic and linolenic acids from the mixture using methanol crystallization and to produce palmitic acid 97.6\%. Preparative high performance liquid chromatography can also be applied to purify palmitic acid and produce $99.9 \%$. In this study, the percentage of palmitic acid that was obtained in the product can be sold commercially because some companies sell palmitic acid with $95 \%$.

\subsection{Response surface methodology (RSM)}

Based on the above results, FAs-to-MeOH ratio $\left(X_{1}\right)$, temperature $\left(X_{2}\right)$ and time $\left(\mathrm{X}_{3}\right)$ significantly affect the yield of SFAs $\left(Y_{1}\right)$, SFAs \% $\left(Y_{2}\right)$ and PA $\%\left(Y_{3}\right)$ in the solid fraction. The interaction among these three factors was carried out using the RSM with the D-optimal design to optimize palmitic acid separation. The ranges of each independent factor are presented in Table 2.

\subsection{Regression model analysis development}

In this study, the software Design-Expert version 6.0.10 (Stat Ease, USA) was applied for performing the D-optimal design. In addition, the RSM was conducted using three independent variables that affected the yield of SFAs $\left(Y_{1}\right)$, SFAs $\%\left(Y_{2}\right)$ and PA $\%\left(Y_{3}\right)$, namely FAs-to-MeOH ratio $\left(X_{1}\right)$, temperature $\left(X_{2}\right)$ and time $\left(Y_{3}\right)$. The D-optimal design analysis showed a total of 18 experiments which were intended to estimate the coefficients of all models by using a quadratic polynomial regression model.

A complex relationship among the independent variables $\left(X_{1}, X_{2}\right.$ and $\left.X_{3}\right)$ that includes both firstand second-order polynomials can be observed in Equations 2, 3, and 4 as the yield \% of SFAs $\left(Y_{1}\right)$, SFAs $\%\left(Y_{2}\right)$, PA $\%\left(Y_{3}\right)$ in the solid fraction:

$$
\begin{aligned}
Y_{1}= & +73.75-0.15 X_{1}-1.01 X_{2}+7.71 X_{3} \\
& +1.68 X_{1}^{2}+2.14 X_{2}^{2}-3.57 X_{3}^{2}-3.15 X_{1} X_{2} \\
& -0.40 X_{1} X_{3}-2.55 X_{2} X_{3}
\end{aligned}
$$




$$
\begin{aligned}
Y_{2}= & +98.81+0.42 X_{1}-0.19 X_{2}-0.079 X_{3} \\
& +0.15 X_{1}^{2}-0.29 X_{2}^{2}+0.55 X_{3}^{2}+0.12 X_{1} X_{2} \\
& +0.27 X_{1} X_{3}-0.093 X_{2} X_{3} \\
Y_{3}= & +91.88+0.45 X_{1}-0.61 X_{2}+0.022 X_{3} \\
& +1.45 X_{1}^{2}-1.15 X_{2}^{2}+2.32 X_{3}^{2}+0.10 X_{1} X_{2} \\
& +0.43 X_{1} X_{3}-0.55 X_{2} X_{3}
\end{aligned}
$$

Regression of coefficients and analysis of variance (ANOVA) of the model for the yield $\%$ of SFAs, SFAs $\%$, and PA \% are listed in Tables 6,7, and 8 , respectively.

The independent variables were used to obtain the R-squared values which measure the amount of reduction in the variability of responses, where a high $\mathrm{R}^{2}$ correlation value of the model indicates that it has a good fit. In addition, the adjusted $\mathrm{R}$-squared correlation can be utilized to determine the fit of a regression model (Zhang and Zheng, 2009). The model was highly significant in terms of $Y_{1}, Y_{2}$, and $Y_{3}$, with R-squared values of 0.98 , 0.94 , and 0.95 , respectively. In this study, R-squared values for all responses show a good correlation between the predicted values and the actual results of the dependent variables derived from the model (Weisberg, 2005). Regarding the yield of SFAs $\left(Y_{1}\right)$, the R-square value of 0.98 shows that the model is capable of explaining about $98 \%$ of the variation in the response, and only $2 \%$ of the variation was not described by the model. The adjusted R- squared value (adj. $\mathrm{R}$-squared $=0.97$ ) shows that the model is significant and its value is close to the $\mathrm{R}$-squared value of 0.98 . Furthermore, concerning the percentage of SFAs $\left(Y_{2}\right)$, the R-square value of 0.94 shows that the model is capable of explaining about $94 \%$ of the variation in the response, and only $6 \%$ of the variation was not explained by the model. The adjusted $\mathrm{R}$ - squared value (adj. $\mathrm{R}$-squared $=0.88$ ) indicates that the model is significant and its value is slightly close to the R-squared value of 0.94 . In addition, in terms of percentage of PA $\left(Y_{3}\right)$, the $\mathrm{R}$-square value of 0.95 shows that the model is capable of explaining about $95 \%$ of the variation in the response, and only $5 \%$ of the total variation was not described by the model. The adjusted R-squared value (adj. R-squared $=0.90$ ) illustrates that the model is significant and its value is slightly close to the R-squared value of 0.95 .

The quadratic regression coefficient was achieved by using a minimal squares method in order to predict the quadratic polynomial models for the yield $\%$ of SFAs $\left(Y_{1}\right)$, SFAs \% $\left(Y_{2}\right)$, and PA \% $\left(Y_{3}\right)$, in the solid fraction as shown in Tables 6,7 and 8, respectively.

The analysis of $F$-value for these coefficients showed that the yields \% of SFAs $\left(Y_{1}\right)$, SFAs $\%$ $\left(Y_{2}\right)$ and PA \% $\left(\mathrm{Y}_{3}\right)$ are highly significant as indicated by the $\mathrm{p}$-value $(\mathrm{p}<0.01)$. The linear effect of FAs on $\mathrm{MeOH}$ ratio $\left(X_{1}\right)$ was highly significant

TABLE 6. ANOVA for response surface quadratic model for (yield $\%$ of SFAs, $Y_{1}$ ) in solid fractionation experiment of high free acid crude palm oil

\begin{tabular}{lcccccc}
\hline Source & SS & DF & MS & $F$-Value & Prob> F & Status \\
\hline Model & 1224.52 & 9 & 136.06 & 63.40 & $<0.0001^{* * *}$ & significant \\
$X_{1}$ & 0.28 & 1 & 0.28 & 0.13 & 0.7263 & $0.0319^{* * *}$ \\
$X_{2}$ & 14.43 & 1 & 14.43 & 6.73 & $<0.0001^{* * *}$ \\
$X_{3}$ & 762.81 & 1 & 762.81 & 355.44 & 0.1355 \\
$X_{1}^{2}$ & 5.91 & 1 & 5.91 & 2.76 & 0.0932 \\
$X_{2}^{2}$ & 7.79 & 1 & 7.79 & 3.63 & $0.0077^{* * *}$ \\
$X_{3}^{2}$ & 26.85 & 1 & 26.85 & 12.51 & $<0.0001^{* * *}$ \\
$X_{1} X_{3}$ & 120.72 & 1 & 120.72 & 56.25 & 0.3907 \\
$X_{1} X_{3}$ & 1.77 & 1 & 1.77 & 0.82 & $0.0003^{* * *}$ \\
$X_{2} X_{3}$ & 78.83 & 1 & 78.83 & 36.73 & \\
Residual & 17.17 & 8 & 2.15 & & 0.5450 \\
Lack of Fit & 8.07 & 4 & 2.02 & 0.89 & not significant \\
Pure Error & 9.10 & 4 & 2.27 & & 24.295 \\
Cor Total & 1241.68 & 17 & & & \\
Std. dev. & 1.46 & Mean & 73.66 & Adequate precision & \\
$\mathrm{R}^{2}$ & 0.98 & $\mathrm{R}_{\text {Adj. }}^{2}$ & 0.97 & & & \\
\hline
\end{tabular}

Notes: $\mathrm{SS}=$ sum of squares, $\mathrm{DF}=$ Degree of freedom, $\mathrm{MS}=$ Mean square, ${ }^{* * *} \mathrm{P}<0.01, * * \mathrm{P}<0.05$ 
Optimization of methanol crystallization for highly efficient separation of palmitic acid from palm fatty acid $\bullet 9$

TABLE 7. ANOVA for response surface quadratic model for (percentage of SFAs, $Y_{2}$ ) in solid fractionation experiment of high free acid crude palm oil

\begin{tabular}{|c|c|c|c|c|c|c|}
\hline Source & SS & DF & MS & F Value & Prob $>$ F & Status \\
\hline Model & 4.99 & 9 & 0.55 & 14.97 & $0.0004 * * *$ & significant \\
\hline$X_{1}$ & 2.25 & 1 & 2.25 & 60.76 & $<0.0001 * * *$ & \\
\hline$X_{2}$ & 0.50 & 1 & 0.50 & 13.48 & $0.0063 * * *$ & \\
\hline$X_{3}$ & 0.08 & 1 & 0.08 & 2.17 & 0.1790 & \\
\hline$X_{1}^{2}$ & 0.05 & 1 & 0.05 & 1.30 & 0.2879 & \\
\hline$X_{2}^{2}$ & 0.14 & 1 & 0.14 & 3.91 & 0.0834 & \\
\hline$X_{3}^{2}$ & 0.63 & 1 & 0.63 & 16.99 & $0.0033 * * *$ & \\
\hline$X_{1} X_{2}$ & 0.16 & 1 & 0.16 & 4.40 & 0.0692 & \\
\hline$X_{1} X_{3}$ & 0.82 & 1 & 0.82 & 22.11 & $0.0015 * * *$ & \\
\hline$X_{2} X_{3}$ & 0.10 & 1 & 0.10 & 12.82 & 0.1316 & \\
\hline Residual & 0.32 & 8 & 0.037 & & & \\
\hline Lack of Fit & 0.24 & 4 & 0.060 & 2.88 & 0.0906 & not significant \\
\hline Pure Error & 0.055 & 4 & 0.021 & & & \\
\hline Cor Total & 5.28 & 17 & & & & \\
\hline Std. dev. & 0.19 & Mean & 99.08 & Adequate precision & 13.524 & \\
\hline $\mathrm{R}^{2}$ & 0.94 & $\mathrm{R}_{\text {Adj. }}^{2}$ & 0.88 & & & \\
\hline
\end{tabular}

TABLE 8. ANOVA for response surface quadratic model for (percentage of PA, $Y_{3}$ ) in solid fractionation experiment of high free acid crude palm oil

\begin{tabular}{|c|c|c|c|c|c|c|}
\hline Source & SS & DF & MS & F Value & Prob $>$ F & Status \\
\hline Model & 31.42 & 9 & 3.49 & 18.50 & $0.0002 * * *$ & significant \\
\hline$X_{1}$ & 2.63 & 1 & 2.63 & 13.92 & $0.0058 * * *$ & \\
\hline$X_{2}$ & 5.22 & 1 & 5.22 & 27.70 & $0.0008 * * *$ & \\
\hline$X_{3}$ & $6.197 \mathrm{E}-003$ & 1 & $6.197 \mathrm{E}-003$ & 0.033 & 0.8607 & \\
\hline$X_{1}^{2}$ & 4.40 & 1 & 4.40 & 23.33 & $0.0013 * * *$ & \\
\hline$X_{2}^{2}$ & 2.27 & 1 & 2.27 & 12.05 & $0.0084 * * *$ & \\
\hline$X_{3}^{2}$ & 11.31 & 1 & 11.31 & 59.93 & $<0.0001 * * *$ & \\
\hline$X_{1} X_{2}$ & 0.13 & 1 & 0.13 & 0.70 & 0.4282 & \\
\hline$X_{1} X_{3}$ & 2.07 & 1 & 2.07 & 11.00 & $0.0106 * *$ & \\
\hline$X_{2} X_{3}$ & 3.71 & 1 & 3.71 & 19.69 & $0.0022 * * *$ & \\
\hline Residual & 1.51 & 8 & 0.19 & & & \\
\hline Lack of Fit & 1.05 & 4 & 0.26 & 2.28 & 0.2221 & not significant \\
\hline Pure Error & 0.46 & 4 & 0.11 & & & \\
\hline Cor Total & 32.93 & 17 & & & & \\
\hline Std. Dev. & 0.43 & Mean & 93.85 & Adequate Precision & 19.555 & \\
\hline $\mathrm{R}^{2}$ & 0.95 & $\mathrm{R}_{\text {Adj. }}^{2}$ & 0.90 & & & \\
\hline
\end{tabular}


$(\mathrm{p}<0.01)$ for percentages of SFAs $\left(Y_{2}\right)$ and PA $\left(Y_{3}\right)$. The linear effect of the temperature $\left(X_{2}\right)$ was also highly significant $(\mathrm{p}<0.01)$ for percentages of SFAs $\left(Y_{2}\right)$ and PA $\%\left(Y_{3}\right)$. The linear effect of the temperature $\left(X_{2}\right)$ was significant $(\mathrm{p}<0.05)$ for the yields $\%$ of SFAs $\left(Y_{1}\right)$, SFAs $\%\left(Y_{2}\right)$. The quadratic effect of FAs on the $\mathrm{MeOH}$ ratio was highly significant $(\mathrm{p}<0.01)$ for PA $\%\left(Y_{3}\right)$. The quadratic effect of the temperature $\left(X_{2}\right)$ was highly significant $(\mathrm{p}<0.01)$ for PA $\%\left(Y_{3}\right)$. The quadratic effect of the time factor $\left(X_{3}\right)$ was also highly significant $(\mathrm{p}<0.01)$ for the yields $\%$ of SFAs $\left(Y_{1}\right)$, SFAs $\%$ $\left(Y_{2}\right), \mathrm{PA} \%\left(Y_{3}\right)$.

The interaction effect among FAs-to-MeOH ratio $\left(X_{1}\right)$ and temperature $\left(X_{2}\right)$ was highly significant $(\mathrm{p}<0.01)$ for the yield of SFAs $\left(Y_{1}\right)$. The interaction effect between temperature $\left(X_{2}\right)$ and time $\left(X_{3}\right)$ was also highly significant $(\mathrm{p}<0.01)$ for the yield $\%$ of SFAs $\left(Y_{1}\right)$, SFAs $\%\left(Y_{2}\right)$ and PA $\%\left(Y_{3}\right)$. Finally, the interaction effect among FAs-to-MeOH ratio $\left(X_{1}\right)$ and time $\left(X_{3}\right)$ was highly significant $(\mathrm{p}<0.01)$ for SFAs $\%\left(Y_{2}\right)$ while the interaction effect between FAs-to-MeOH ratio $\left(X_{1}\right)$ and time $\left(X_{3}\right)$ was significant $(\mathrm{p}<0.05)$ for PA $\%\left(Y_{3}\right)$.

The results of ANOVA further achieved support the significance and the fitness of the quadratic model. The ANOVA of the quadratic regression model demonstrates that the model is highly significant, which is observable from the low p-value of the Fishers-test (F-test) $(\mathrm{p}<0.01)$. The ANOVA for the response surface quadratic model is represented in Tables 6, 7, and 8 .

The $F$-value for lack-of-fit for all the dependent variables (Table 6, 7 and 8) demonstrated that lack of fit is insignificant ( $p$-value $>0.05$ ). This insignificant lack of fit is relative to the pure error (Zhang and Zheng, 2009), which implies that all the models predicted for the dependent variables were satisfactorily fitted to the experimental data.

The adequate precision value estimates the signal-to-noise ratio, and a value higher than 4 is acceptable in enhancing the fitness of the quadratic model. Tables 6,7 , and 8 show that the adequate precision values for (yield $\%$ of SFAs, $Y_{1}$ ), (SFAs $\left.\%, Y_{2}\right)$, and (PA $\%, Y_{3}$ ) were of $24.295,13.524$, and 19.555 , respectively.

The yield of the SFAs $\%\left(Y_{1}\right)$ changed significantly from 60.8 to $87.5 \%$ when the FAs-to-MeOH ratio $\left(X_{1}\right)$, temperature $\left(X_{2}\right)$ and time $\left(X_{3}\right)$ were varied, as displayed in Table 5. Moreover, the ANOVA of the model indicates that the quadratic term of time $\left(X_{3}\right)$ on the yield of SFAs $\left(Y_{1}\right)$ was highly significant $(\mathrm{p}<$ $0.01)$, which means that this variable had a considerable effect on the yield of SFAs $\left(Y_{1}\right)$. However, the quadratic effect of the FAs-to-MeOH $\left(X_{1}\right)$ and temperature $\left(X_{2}\right)$ was not significant $(\mathrm{p}>0.05)$, thus suggesting that these factors had little effect on the yield of SFAs $\left(Y_{1}\right)$ within the study ranges. Furthermore, the interaction effect between FAs-to-MeOH $\left(X_{1}\right)$ and time $\left(X_{2}\right)$ and the interaction effect between temperature $\left(X_{2}\right)$ and time $\left(X_{3}\right)$ on the yield of SFAs $\left(Y_{1}\right)$ were highly significant $(\mathrm{p}<0.01)$, whereas the interaction effect between the FAs-to-MeOH $\left(X_{1}\right)$ and time $\left(X_{3}\right)(\mathrm{p}>0.05)$ was insignificant as predicted by the quadratic model effect (Table 6).

The SFAs \% $\left(Y_{2}\right)$ varied significantly from 98 to $100 \%$ when the FAs-to-MeOH ratio $\left(X_{1}\right)$, temperature $\left(X_{2}\right)$ and time $\left(X_{3}\right)$ were varied, as given in Table 5. The ANOVA of the model showed that the quadratic term of time $\left(X_{3}\right)$ on the percentage of SFAs $\left(Y_{2}\right)$ was highly significant $(\mathrm{p}<0.01)$, which indicates that these variables had a considerable effect on the percentage of SFAs $\left(Y_{2}\right)$ within the study ranges. Nevertheless, the quadratic term of the FAs-to-MeOH $\left(X_{1}\right)$ and temperature $\left(X_{2}\right)$ was insignificant $(\mathrm{p}>0.05)$, thus illustrating that these factors had little effect on the percentage of SFAs $\left(Y_{2}\right)$. Moreover, the interaction effect between FAs-to-MeOH $\left(X_{1}\right)$ and time $\left(X_{3}\right)$ on the percentage of SFAs $\left(Y_{2}\right)$ was highly significant $(\mathrm{p}<0.01)$, whereas the interaction effect between the FAs-to$\mathrm{MeOH}\left(X_{1}\right)$ and temperature $\left(X_{2}\right)(\mathrm{p}>0.05)$ and the interaction effect between FAs-to-MeOH $\left(X_{1}\right)$ and temperature $\left(X_{2}\right)$ were insignificant as estimated by the quadratic model effect (Table 7).

In this study, the percentage of $\mathrm{PA} \%\left(Y_{3}\right)$ varied significantly from 90.1 to $96.7 \%$ when the FAs-to$\mathrm{MeOH}$ ratio $\left(X_{1}\right)$, temperature $\left(X_{2}\right)$ and time $\left(X_{3}\right)$ were varied as displayed in Table 5. The ANOVA of the model shows that the quadratic effect of FAsto-MeOH $\left(X_{1}\right)$, temperature $\left(X_{2}\right)$ and time $\left(X_{3}\right)$ on the percentage of PA $\left(Y_{2}\right)$ was highly significant $(\mathrm{p}<0.01)$, which suggests that these variables had considerable impact on the percentage of PA $\left(Y_{3}\right)$. The results also show that the interaction effect between temperature $\left(X_{2}\right)$ and time $\left(X_{3}\right)$ on the percentage of PA $\left(Y_{3}\right)$ was highly significant $(\mathrm{p}<0.01)$, while the interaction effect between FAs-to-MeOH $\left(X_{1}\right)$ and time $\left(X_{3}\right)$ on the percentage of PA $\left(Y_{3}\right)$ was significant $(\mathrm{p}<0.05)$. It was also found that the interaction effect between FAs-to-MeOH $\left(X_{1}\right)$ and temperature $\left(X_{2}\right)(\mathrm{p}>0.05)$ was insignificant as estimated by the quadratic model effect (Table 8 ).

\subsection{Optimizations and response surface plotting}

The three-dimensional (3D) response surfaces for the yield $\%$ of SFAs $\left(Y_{1}\right), \operatorname{SFAs} \%\left(Y_{2}\right)$, and PA $\%\left(Y_{3}\right)$ were constructed based on the model equations (Eq. (2), (3) and (4) to visualize the interaction between variables and to verify the optimal value of each variable for the maximum yield of SFAs $\left(Y_{1}\right)$, maximum percentage of SFAs $\left(Y_{2}\right)$ and maximum percentage of PA $\left(Y_{3}\right)$ using crystallization of palm saturated fatty acids from methanol. In the $3 \mathrm{D}$ graphs, the interaction between two variables was plotted, whereas another factor was kept constant at its central level. The central values were 1:15 $(\mathrm{g} / \mathrm{mL})$ of FAs-to-MeOH, -7.5 
${ }^{\circ} \mathrm{C}$ of crystallization temperature, and 16 h of crystallization time as shown in Table 2.

The interaction effect between FAs-to-MeOH ratio and temperature is shown Figure 2a. The 3D plot shows that increasing the ratio of methanol from $10 \mathrm{~mL}$ to $20 \mathrm{~mL}$ continuously improved the yield \% of SFAs. Moreover, increasing the temperature from $-15{ }^{\circ} \mathrm{C}$ to $0{ }^{\circ} \mathrm{C}$ gradually improved the yield $\%$ of SFAs. The effect of methanol ratio and time led to an increase in yield $\%$ of SFAs with an increase in methanol ratio and time (Figure $2 \mathrm{~b}$ ). The effect of temperature and time also resulted in increasing the yield $\%$ of SFAs with an increase in methanol ratio and time (Figure 2c).

The maximum SFAs $\%$ as $99.9 \%$ was obtained at a methanol ratio of $20 \mathrm{~mL}$ and temperature of $-3.75^{\circ} \mathrm{C}$ (Figure 3a). The 3D graph shows that the maximum SFAs \% was obtained at the methanol ratio of $20 \mathrm{~mL}$ and time of $24 \mathrm{~h}$ (Figure $3 \mathrm{~b}$ ). The combined effect between temperature and time demonstrated
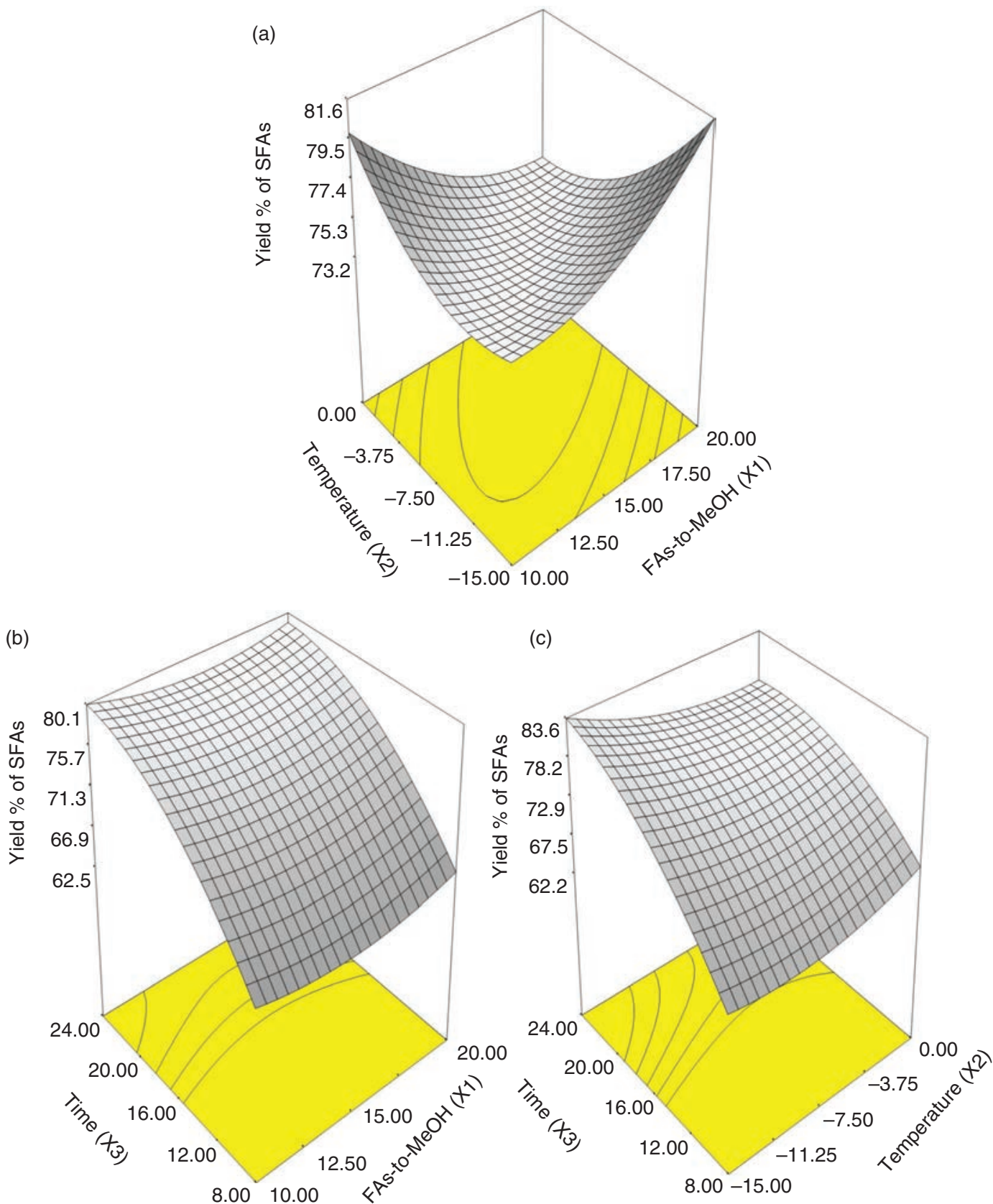

FIGURE 2. A three-dimensional response surface (3D) of the yield \% of SFAs $\left(Y_{1}\right)$ as a function of FAs-to MeOH ratio $\left(X_{1}\right.$, w/v) and temperature $\left(X_{2},{ }^{\circ} \mathrm{C}\right)(\mathrm{a}), \mathrm{FAs}$-to $\mathrm{MeOH}$ ratio $\left(X_{1}, \mathrm{w} / \mathrm{v}\right)$ and time $\left(X_{3}, \mathrm{~h}\right)(\mathrm{b})$, temperature $\left(X_{2},{ }^{\circ} \mathrm{C}\right)$ and time $\left(X_{3}, \mathrm{~h}\right)(\mathrm{c})$. 


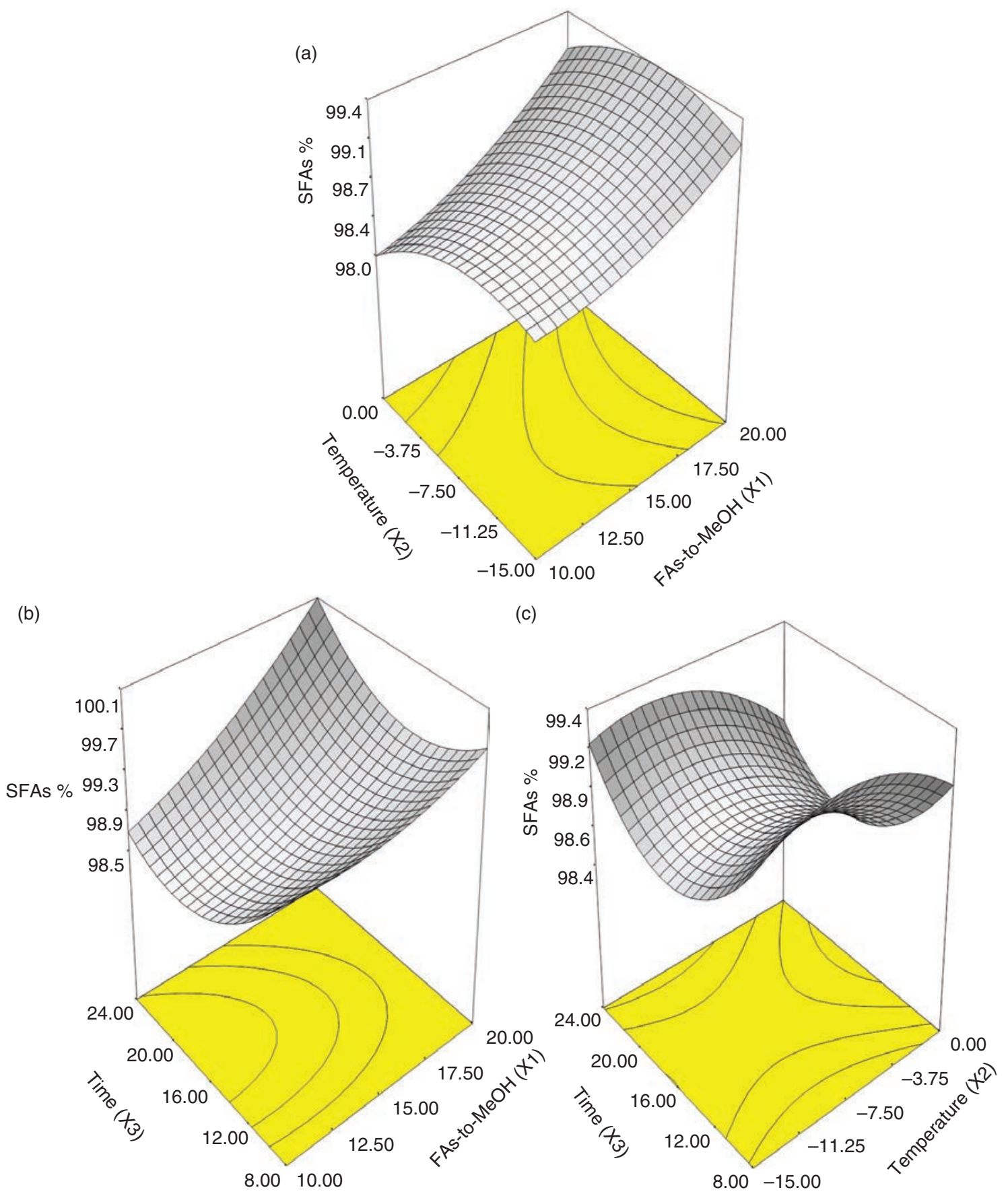

FIGURE 3. A three-dimensional response surface (3D) of SFAs $\%\left(Y_{2}\right)$ as a function of FAs-to MeOH ratio $\left(X_{1}\right.$, w/v) and temperature $\left(X_{2},{ }^{\circ} \mathrm{C}\right)(\mathrm{a})$, FAs-to $\mathrm{MeOH}$ ratio $\left(X_{1}, \mathrm{w} / \mathrm{v}\right)$ and time $\left(X_{3}, \mathrm{~h}\right)(\mathrm{b})$, temperature $\left(X_{2},{ }^{\circ} \mathrm{C}\right)$ and time $\left(X_{3}, \mathrm{~h}\right)(\mathrm{c})$.

that SFAs \% increased with an increase in the time (Figure 3c).

The interaction effect between FAs-to-MeOH ratio and temperature on $\mathrm{PA} \%$ is displayed in Figure $4 \mathrm{a}$. The 3D plot shows that increasing the ratio of methanol from $10 \mathrm{~mL}$ to $20 \mathrm{~mL}$ continuously improved the yield \% of PA, while the optimal temperature for the maximum PA $\%$ was at $-3.75^{\circ} \mathrm{C}$. The effect of methanol ratio and time increased PA $\%$ with an increase methanol ratio from $15 \mathrm{~mL}$ to 20 $\mathrm{mL}$, while the crystallization time improved the PA $\%$ beyond $16 \mathrm{~h}$ (Figure $4 \mathrm{~b}$ ). The effect of temperature and time also led to an increase in PA \% with an increase methanol ratio and time (Figure 4c). 
(a)
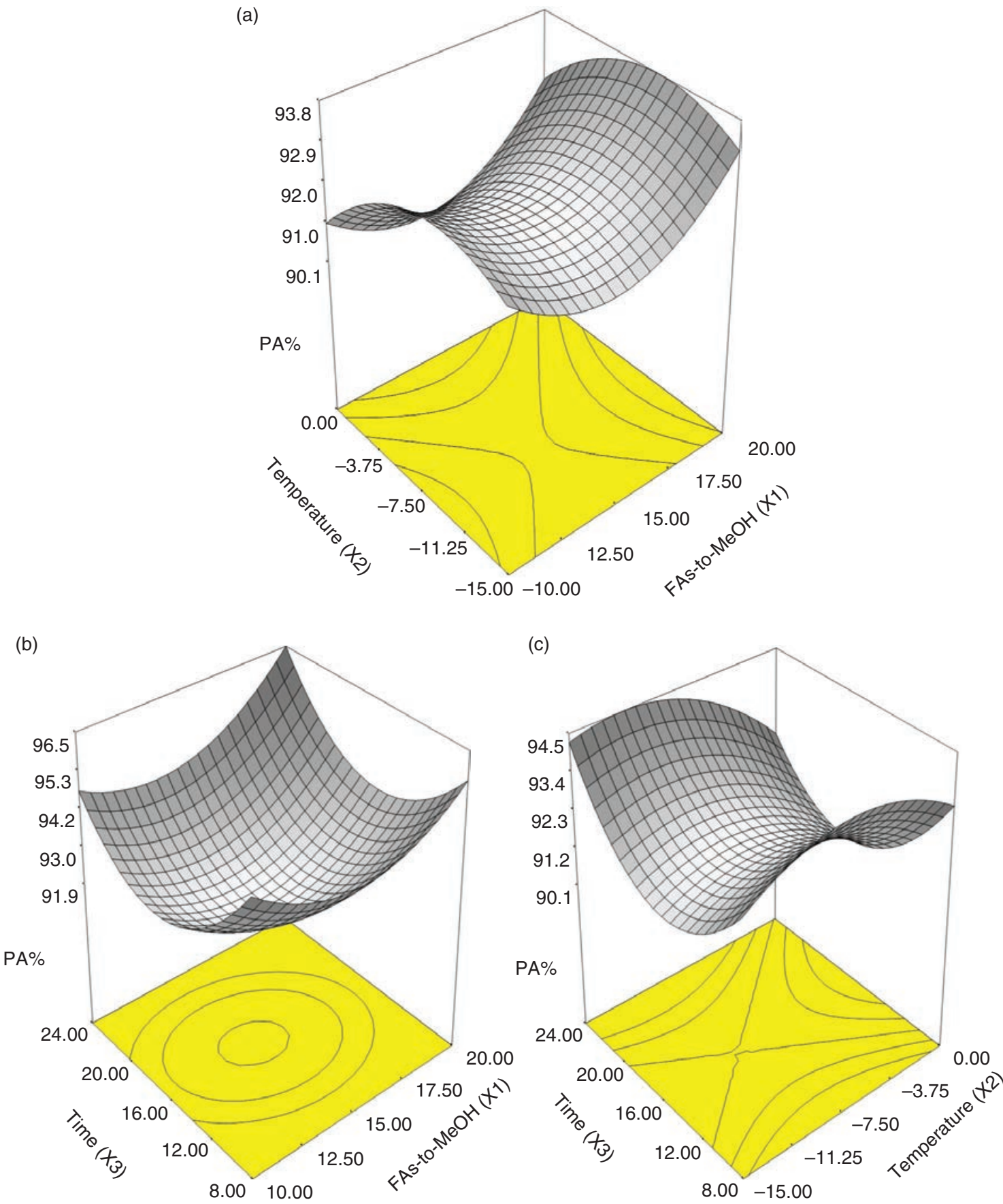

Figure 4. A three-dimensional response surface (3D) of PA \% $\left(Y_{3}\right)$ as a function of FAs-to $\mathrm{MeOH}$ ratio $\left(X_{1}\right.$, w/v) and temperature $\left(X_{2},{ }^{\circ} \mathrm{C}\right)(\mathrm{a})$, FAs-to MeOH ratio $\left(X_{1}\right.$, w/v) and time $\left(X_{3}, \mathrm{~h}\right)(\mathrm{b})$, temperature $\left(X_{2},{ }^{\circ} \mathrm{C}\right)$ and time $\left(X_{3}, \mathrm{~h}\right)(\mathrm{c})$.

\subsection{Model verification}

The desirability function was used to test the validity of the predicted models developed to determine the optimal conditions for the response variables: yield \% of SFAs, percentage of SFAs and percentage of palmitic acid with maximum values as shown in Table 9. A validation test was carried out to confirm the validity of the predicted model. A triplicate investigation was carried out under optimum conditions, comprising a fatty acidsto-methanol ratio of $1: 20(\mathrm{w} / \mathrm{v})$, crystallization 
temperature of $-14.75{ }^{\circ} \mathrm{C}$, and crystallization time of 24 hours. As shown in Table 10, a yield $\%$ of approximately $87.2 \pm 0.3 \%$ was obtained from a solid fraction of the SFAs at the optimized methanol crystallization condition in addition to $95.7 \pm 0.9 \%$ of palmitic acid.

\subsection{Gas chromatography analysis of fatty acids}

The composition of fatty acids was verified after transesterification using the GC-FID analysis. The chromatogram in Figure 5 and Table 5 denotes the number run of 11. It can be noted that, for the PA composition in the solid fraction after purification was increased from $90 \%$ to $96.7 \%$, the SA composition decreased from $5.8 \%$ to $3.3 \%$. There is no

TABLE 9. Optimization criteria for dependent variables

\begin{tabular}{llcc}
\hline Variables & Goal & $\begin{array}{c}\text { Lower } \\
\text { limits }\end{array}$ & $\begin{array}{c}\text { Upper } \\
\text { limits }\end{array}$ \\
\hline $\begin{array}{l}\text { FAs-to-methanol ratio } \\
(\mathrm{w} / \mathrm{v}),\left(X_{1}\right)\end{array}$ & $\begin{array}{l}\text { in the } \\
\text { range }\end{array}$ & 10 & 20 \\
$\begin{array}{l}\text { Crystallization } \\
\text { temperature }\left({ }^{\circ} \mathrm{C}\right),\left(X_{2}\right)\end{array}$ & $\begin{array}{l}\text { in the } \\
\text { range }\end{array}$ & -15 & 0 \\
$\begin{array}{l}\text { Crystallization time }(\mathrm{h}), \\
\left(X_{3}\right)\end{array}$ & $\begin{array}{l}\text { in the } \\
\text { range }\end{array}$ & 8 & 24 \\
$\begin{array}{l}\text { Yield \% of SFAs, }\left(Y_{1}\right) \\
\text { maximize }\end{array}$ & 60.8 & 87.5 \\
PAs $\%,\left(Y_{2}\right)$ & $\begin{array}{l}\text { maximize } \\
\text { maximize }\end{array}$ & 98 & 100 \\
\hline & & & 96.1 \\
\hline
\end{tabular}

observed oleic acid where the OA composition was decreased from $4.2 \%$ to $0.0 \%$.

\subsection{Iodine value}

The iodine value indicates the level of unsaturation in the sample. Figure 6 illustrates the variation in the iodine value of PFAM, SFAs after crystallization from methanol was conducted. It can be observed that the iodine value decreased gradually with repeated crystallization due to the decreased concentration of USFAs in the solid fraction after conducting methanol crystallization. The iodine value of the final product is $0.9 \pm 0.3 \mathrm{~g} / 100 \mathrm{~g}$, which approves removing the USFAs from the solid fraction.

\section{CONCLUSION}

Palmitic acid was successfully separated with high efficiency and maximum concentration. Methanol crystallization is a promising method to obtain a highly concentrated PA as a major component in SFAs in a solid fraction from a mixture of palm fatty acids. This has potential for enhancing the value of the large-scale production of PA. This method is one of the most efficient methods that could be applied to the separation of fatty acids. This study provides a simple and effective process for improving purified PA, which ultimately reaches $96.7 \%$ as compared to $42 \%$ of PA achieved using a non-optimized process.

TABLE 10. Result of model validation at the optimum condition (Verification test)

\begin{tabular}{lcccccc}
\hline Factors & FAs-to-methanol ratio $(\mathbf{w} / \mathbf{v})\left(X_{1}\right)$ & $\begin{array}{c}\text { Temperature } \\
\left({ }^{\circ} \mathbf{C}\right)\left(X_{2}\right)\end{array}$ & Time $(\mathbf{h})\left(X_{3}\right)$ & SFAs Yield \% $\left(Y_{1}\right)$ & SFAs \% $\left(Y_{2}\right)$ & PA \% $\left(Y_{3}\right)$ \\
\hline Predicted & 20 & -14.75 & 24 & 87.4 & 100 & 96.5 \\
Actual & 20 & -14.75 & 24 & $87.2 \pm 0.3$ & $99.9 \pm 0.1$ & $95.7 \pm 0.9$ \\
\hline
\end{tabular}

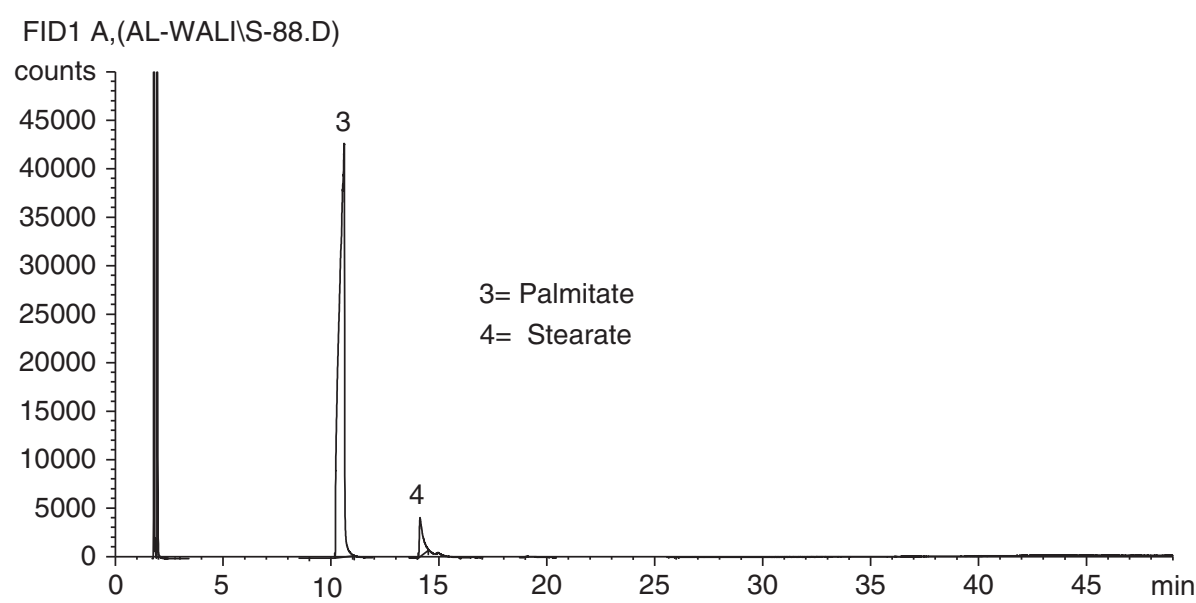

FIGURE 5. GC chromatogram of palmitic acid after purification at the optimal conditions. 


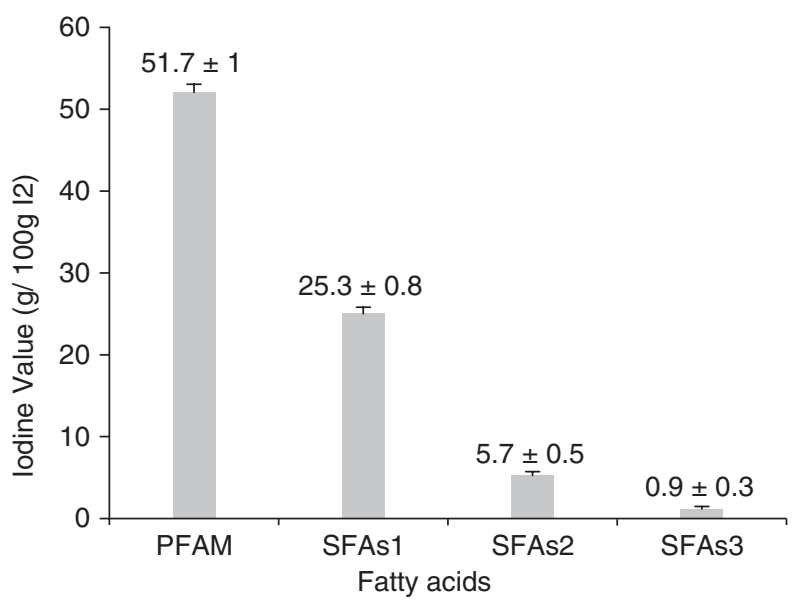

FiguRE 6. Iodine value of fatty acids before and after methanol crystallization.

\section{ACKNOWLEDGMENTS}

The authors appreciatively acknowledge Universiti Kebangsaan Malaysia for the financial and technical support in carrying out this research. Specifically, we thank Advanced Medical and Dental Institute (AMDI), Universiti Sains Malaysia (USM), and Ministry of Science, Technology and Innovation (MOSTI) of Malaysia, which funded this project via grant \# GUP2016-063 and Sime Darby Sdn Bhd via grant \# ST-2014-01. Thanks are also due to the Faculty of Education, Thamar University, Thamar, Yemen for supporting this research.

\section{REFERENCES}

Ba-Abbad MM, Kadhum AAH, Mohamad AB, Takriff MS, Sopian K. 2013. Optimization of process parameters using $\mathrm{D}$-optimal design for synthesis of $\mathrm{ZnO}$ nanoparticles via sol-gel technique. J. Ind. Eng. Chem. 19, 99-105. https:// doi.org/10.1016/j.jiec.2012.07.010

Box GEP, Hunter WG, Hunter JS. 1978. Statistics for experimenters: an introduction to design, data analysis, and model building: Wiley Interscience.

Brown J, Kolb DK. 1955. Applications of low temperature crystallization in the separation of the fatty acids and their compounds. Prog. Chem. Fats Lipids. 3, 57-94. https://doi. org/10.1016/0079-6832(55)90004-5

Bowden NB, Gupta A. 2014. Methods for Separating Mixtures of Compounds, Google Patents.

Cermak SC, Kenar JA, Evangelista RL. 2012. Distillation of natural fatty acids and their chemical derivatives: INTECH Open Access Publisher.

Chu B, Quek S, Baharin B. 2003. Optimization of enzymatic hydrolysis for concentration of vitamin $\mathrm{E}$ in palm fatty acid distillate. Food Chem. 80, 295-302. https://doi.org/10.1016/ S0308-8146(02)00178-4

Fang G, Li H, Cao L, Shan F. 2012. Preparation and thermal properties of form-stable palmitic acid/active aluminum oxide composites as phase change materials for latent heat storage. Mater. Chem. Phys. 137, 558-564. https://doi. org/10.1016/j.matchemphys.2012.09.058

Henderson, J, Osborne, D J. 2000. The oil palm in all our lives: how this came about. Endeavour 24, 63-68. https://doi. org/10.1016/S0160-9327(00)01293-X
Japir AA-W, Salimon J, Derawi D, Bahadi M, Yusop MR. 2016. Purification of High Free Fatty Acid Crude Palm Oil Using Molecular Distillation. Asian J. Chem. 28, 25492554. https://doi.org/10.14233/ajchem.2016.20095

Japir AA-W, Salimon J, Derawi D, Bahadi M, Al-Shuja'a S, Yusop MR. 2017. Physicochemical characteristics of high free fatty acid crude palm oil. OCL. https://doi. org/10.1051/ocl/2017033

Jiang S, Shao P, Pan L, Zhao Y. 2006. Molecular distillation for recovering tocopherol and fatty acid methyl esters from rapeseed oil deodoriser distillate. Biosystems Eng. 93, 383391. https://doi.org/10.1016/j.biosystemseng.2006.01.008

Kempers P, Schörken U, Wolf T, Sato S, De Almeida WB, Bizzarri PS, Araujo, AS. 2013. Process for production of fatty acids, fatty acid esters and sterolesters from soapstock. Patent No. US8426622 B2.

Maddikeri GL, Pandit AB, Gogate PR. 2012. Adsorptive removal of saturated and unsaturated fatty acids using ion-exchange resins. Ind. Eng. Chem. Res. 51, 6869-6876. https://doi.org/10.1021/ie3000562

Montgomery D. 2001. Design and analysis of experiments $\left(5^{\text {th }}\right.$ ed.). New York, USA Wiley.

Myers RH, Montgomery DC, Anderson-Cook CM. 2009. Response surface methodology: process and product optimization using designed experiments ( ${ }^{\text {rd }}$ ed.): John Wiley \& Sons, USA

Nakahara H, Lee S, Shoyama Y, Shibata O. 2011. The role of palmitic acid in pulmonary surfactant systems by Langmuir monolayer study: Lipid-peptide interactions. Soft Matter 7, 11351-11359. https://doi.org/10.1039/c1sm06345f

Permukaan MKGB, Wong Y, Tan Y, Taufiq-Yap Y, Ramli I. 2015. An Optimization Study for Transesterification of Palm Oil using Response Surface Methodology (RSM). Sains Malaysiana 44, 281-290. https://doi.org/10.17576/jsm-2015-4402-17

Prasanth Kumar P, Gopala Krishna A. 2015. Physicochemical characteristics of commercial coconut oils produced in India. Grasas Aceites 66, e062. https://doi.org/10.3989/gya.0228141

Salimon J, Abdullah BM, Salih, N. 2011. Hydrolysis optimization and characterization study of preparing fatty acids from Jatropha curcas seed oil. Chem. Cent. J. 5, 1-9. https://doi.org/10.1186/1752-153X-5-67

Salimon J, Abdullah BM, Salih N. 2012. Selectively increasing of polyunsaturated (18:2) and monounsaturated (18: 1) fatty acids in Jatropha curcas seed oil by crystallization using D-optimal design. Chem. Cent. J. 6, 1-15. https:// doi.org/10.1186/1752-153X-6-65

Saravanan K, Tyagi B, Shukla RS, Bajaj HC. 2016. Solvent free synthesis of methyl palmitate over sulfated zirconia solid acid catalyst. Fuel 165, 298-305. https://doi.org/10.1016/j. fuel.2015.10.043

Strohmeier K, Schober S, Mittelbach M. 2014. Solvent-assisted crystallization of fatty acid alkyl esters from animal fat. $J$. Am. Oil Chem. Soc. 91, 1217-1224. https://doi.org/10.1007/ s11746-014-2456-8

Wanasundara UN, Wanasundara P, Shahidi F. 2005. Novel Separation Techniques for Isolation and Purification of Fatty Acids and Oil by-Products. Bailey's Industrial Oil and Fat Products

Weisberg S. 2005. Applied linear regression ( ${ }^{\text {rd }}$ ed. Vol. 528): John Wiley \& Sons INC, New York. https://doi. org/10.1002/0471704091

Wu M, Ding H, Wang S, Xu S. 2008. Optimizing conditions for the purification of linoleic acid from sunflower oil by urea complex fractionation. J. Am. Oil Chem. Soc. 85, 677-684. https://doi.org/10.1007/s11746-008-1245-7

Yang K, El-Haik BS. 2009. Design for Six Sigma, A Roadmap for Product Development ( $2^{\text {nd }}$ ed.). United States of America: The McGraw-Hill Companies.

Zhang N, Yuan Y, Yuan Y, Li, T, Cao, X. 2014. Lauric-palmitic-stearic acid/expanded perlite composite as formstable phase change material: Preparation and thermal properties. Energy Buildings 82, 505-511. https://doi. org/10.1016/j.enbuild.2014.07.049

Zhang Z, Zheng H. 2009. Optimization for decolorization of azo dye acid green 20 by ultrasound and $\mathrm{H}_{2} \mathrm{O}_{2}$ using response surface methodology. J. Hazard. Mater. 172, 1388-1393. https://doi.org/10.1016/j.jhazmat.2009.07.146 